\title{
SISTEM KONTROL MESIN FUSED DEPOSITION MODELLING
}

\author{
Cristian Awi, Soeharsono dan Didi Widya Utama \\ Program Studi Teknik Mesin, Fakultas Teknik Mesin, Universitas Tarumanagara
}

\begin{abstract}
Fused deposition modeling is a rapid prototyping process that is very popular. Fused deposition modeling is actually one method of Three -dimensional printing. Fused deposition modeling process, namely by heating the thermoplastic material and then do the printing. Our focus is to learn, the engine control system fused deposition modeling with software arduino 1.6.8 with firmware marlin and other software $3 d$ printer. experimental control system is done by testing the direction of motion and measuring the distance and then test the form . Making fused deposition modeling is intended as a prototype in order to understand the control system and how to innovate in the development of fused deposition modeling. The results of the control system in the form of a fused depositon modeling engine capable of running as expected and can create a physical model.
\end{abstract}

Keywords : 3D printer, Fused Deposition Modelling, Arduino , Prototyping.

\begin{abstract}
Abstrak: Fused deposition modelling merupakan proses rapid prototyping yang sangat populer. Fused deposition modelling sebenarnya merupakan salah satu metode dari Three dimensional printing. Proses Fused deposition modelling yaitu dengan memanaskan bahan thermoplastic kemudian dilakukan proses printing. Fokus kami adalah mempelajari, sistem kontrol mesin fused deposition modelling dengan firmware marlin dengan software Arduino 1.6.8 dan software 3d printer lainnya. percobaan sistem kontrol dilakukan dengan menguji arah gerak dan pengukuran jarak tempuh kemudian pengujian bentuk. Pembuatan fused deposition modelling ini bertujuan sebagai prototype agar dapat mengerti sistem kontrol dan cara melakukan inovasi pada pengembangan fused deposition modelling. Hasil dari sistem kontrol berupa sebuah mesin fused depositon modelling yang mampu berjalan sesuai yang diharapkan dan dapat membuat sebuah model fisik.
\end{abstract}

Kata Kunci : 3D printer, Fused Deposition Modelling, Arduino , Prototyping.

\section{PENDAHULUAN}

Pada masa sekarang ini, perkembangan teknologi sudah semakin pesat. Perkembangan dalam bidang industri pemesinan meliputi pembuatan suatu produk. Pembuatan suatu produk dapat dilakukan dengan berbagai cara. Seperti Rapid Prototyping. Rapid Prototyping sendiri dapat didefinisikan sebagai metode-metode yang digunakan untuk membuat model berskala (Prototype) dari mulai bagian suatu produk maupun rakitan produk secara cepat dengan menggunakan data Computer Aided Design (CAD) tiga dimensi. Rapid Prototyping ini sendiri pun sangat berperan penting dalam perkembangan dalam bidang industri itu sendiri.

Di dalam Rapid Protoyping juga mempelajari tentang 3D Printing yang memiliki prinsip kerja yang sama dengan Rapid Prototyping. Sebenarnya Rapid Prototyping ini sendiri sudah lama di terapkan. Namun masih kurang efektif karena proses pembuatannya yang tergolong sangat lama dalam membua prototype suatu produk. Juga dalam pembuatan suatu prototype ini memiliki biaya yang tidak sedikit. Pembuatan prototype ini sangat berguna karena dapat meningkatkan efektifitas dalam berkomunikasi atau memvisualisasikan suatu produk dalam bentuk berskala dan yang paling penting yaitu dapat meminimalisasikan kesalahan-kesalahan yang terjadi dalam suatu produksi. Rapid Prototyping juga memiliki keunggulan dimana mesin ini dapat mengerjakan suatu produk yang tidak dapat dikerjakan mesin-mesin konvensional.

Dan pada sekarang ini, masih sedikit yang menggunakan mesin rapid prototyping untuk meningkatkan produksinya dikarenakan persiapan dan hasil pengaturannya masih rumit. Artikel ini membahas tentang rapid prototyping berbasis fused deposition modelling. Bagaimana cara kerja dari fused deposition modelling dan hasil dari mesin fused deposition modelling sehingga dapat dilakukan penelitian lebih lanjut. 


\section{METODOLOGI}

Metode yang digunakan dalam penelitian mengenai fused deposition modelling adalah metode analitis dengan menggunakan software perancangan dan simulasi. Berbagai informasi dalam perancangan dan pemilihan komponen-komponen sistem kontrol yaitu Arduino, driver motor stepper, ramps 1.4, limit switch, motor stepper dilakukan melalui studi pustaka melalui buku dan sumber-sumber lain dari internet untuk memaksimalkan hasil perancangan dan menghindari kesalahan yang seharusnya tidak terjadi.

Dari semua komponen yang sudah dilakukan estimasi untuk penggunaan di dalam perancangan, maka sudah dapat dilakukan pengujian terhadap mesin fused deposition modelling. Proses pengujian dilakukan dengan menggunakan software $3 d$ modelling dengan membentuk primitive shape yang kemudian semua akan di analisa kecocokan antara perhitungan pada software dengan bentuk aslinya apakah presisi atau tidak.

Proses perancangan sistem kontrol fused deposition modelling dilakukan mengikuti prosesproses pada diagram alir berikut:

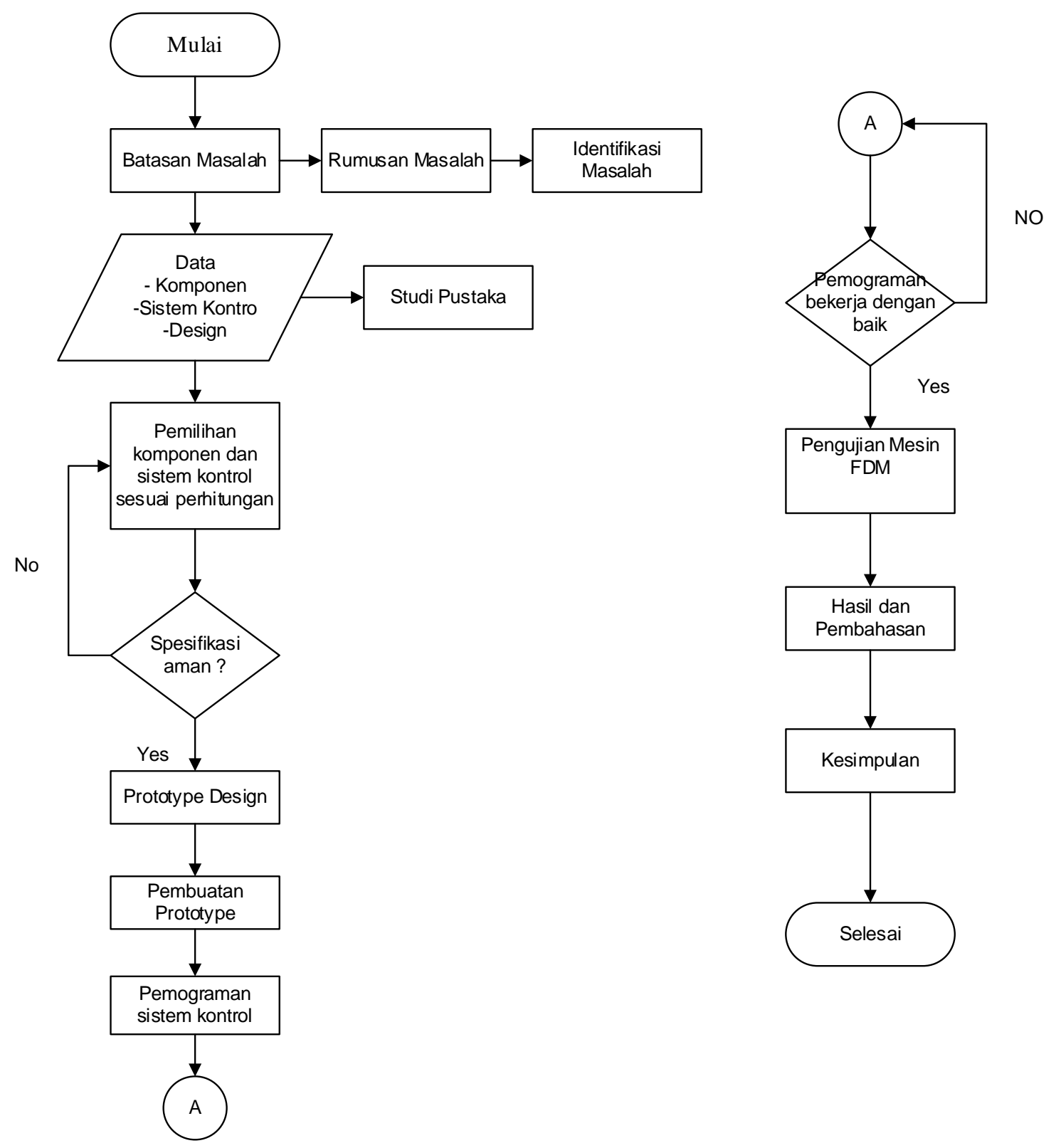

Gambar 1. Diagram alir proses perancangan mesin fused deposition modelling 
Dengan mengikuti proses perancangan mesin fused deposition modelling, didapat bagan sistem kontrol pada mesin fused deposition modelling yang dapat dilihat pada gambar berikut:

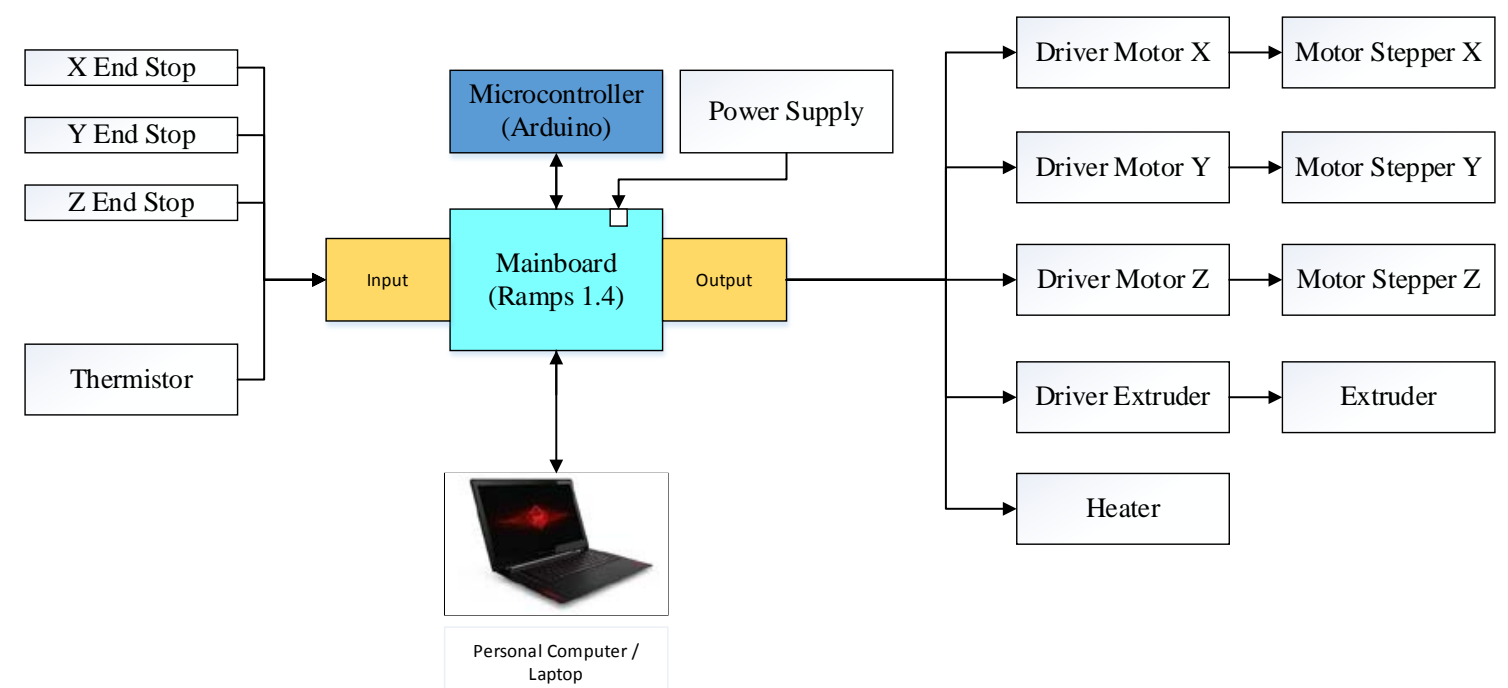

Gambar 2. Bagan sistem kontrol

Adapula tahap-tahap dalam melakukan proses printing dapat dilihat pada diagram alir berikut:

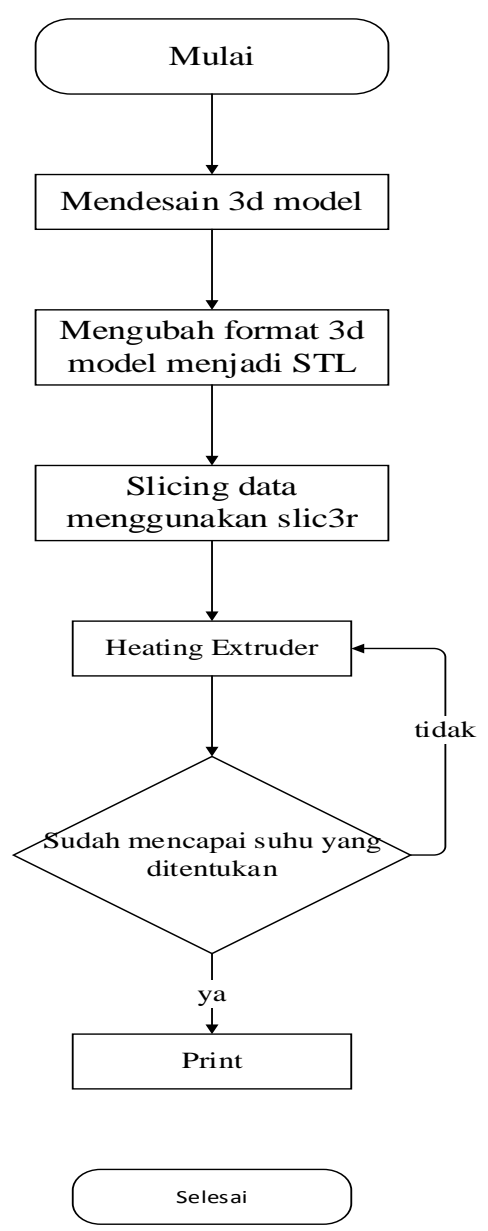

Gambar 3. Diagram alir langkah-langkah printing 


\section{HASIL DAN PEMBAHASAN}

Hasil yang didapat pada sistem kontrol mesin fused deposition modelling yaitu :

\section{Hasil Pengujian Sistem Kontrol}

- Hasil pergerakan sumbu terhadap sumbu X

- Temperatur

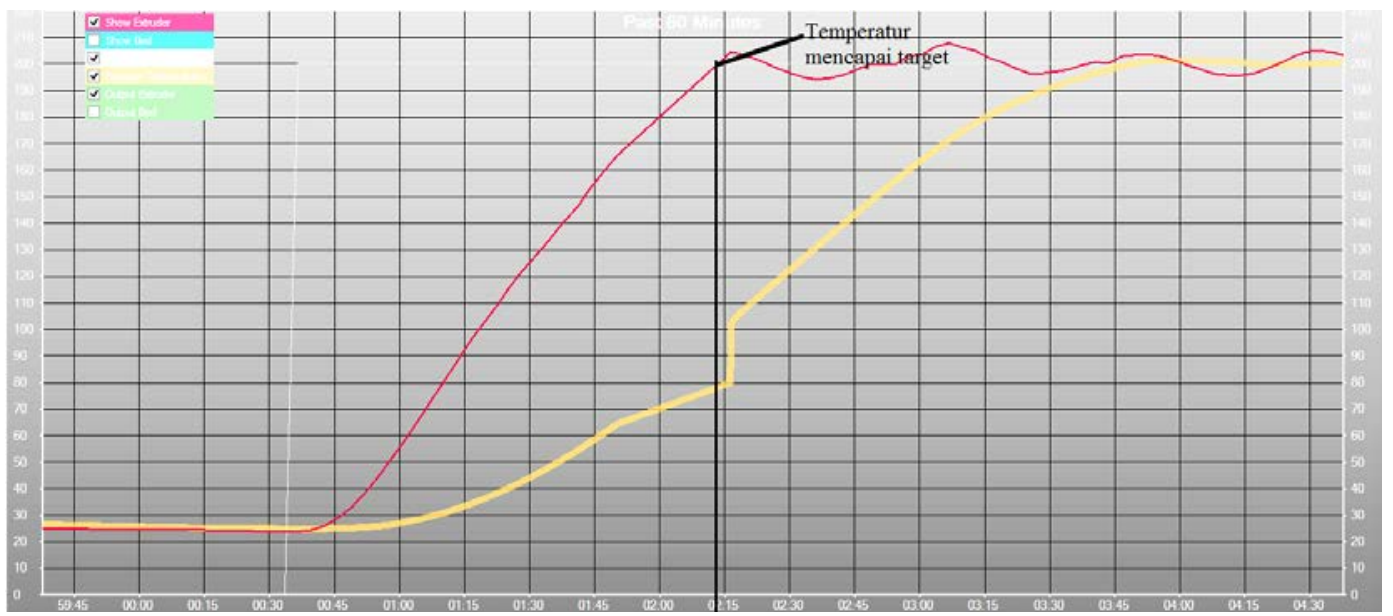

Gambar 4. Grafik waktu terhadap temperatur

Pada saat suhu sudah mencapai target, terdapat kenaikan suhu dan penurunan. Hal ini disebabkan dari nilai PID yang telah d input pada firmware. Untuk mencapai suhu yang stabil nilai PID harus tepat.

\section{Hasil printing}

- Kubus

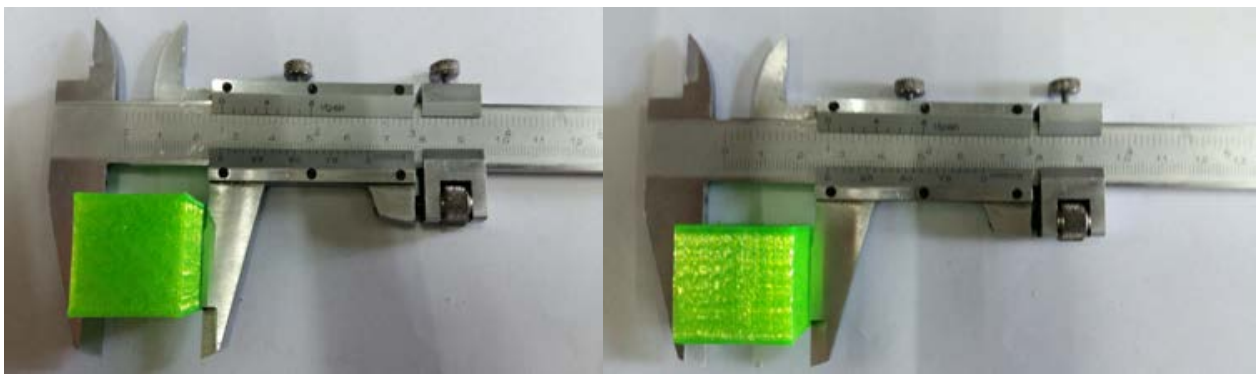

Gambar 5. Kubus

Tabel 1. Hasil Kubus

\begin{tabular}{ccc}
\hline Keterangan & Satuan & Penyimpangan \\
\hline Ukuran Design & $25.4 \times 25.4 \times 25.4$ & \multirow{2}{*}{$2.38 \%$} \\
Ukuran Hasil & $25.6 \times 25.6 \times 25.6$ & \multirow{2}{*}{$23.96 \%$} \\
\hline Waktu Estimasi & 23 menit 1 detik & \\
Waktu Aktual & 28 menit 32 detik & \multirow{2}{*}{$1.24 \%$} \\
\hline Panjang Filament & $3087 \mathrm{~mm}$ & \\
Berat Estimasi & $8.87 \mathrm{~g}$ & \\
Berat Aktual & $8.76 \mathrm{~g}$ & \\
\hline
\end{tabular}

- Tabung 

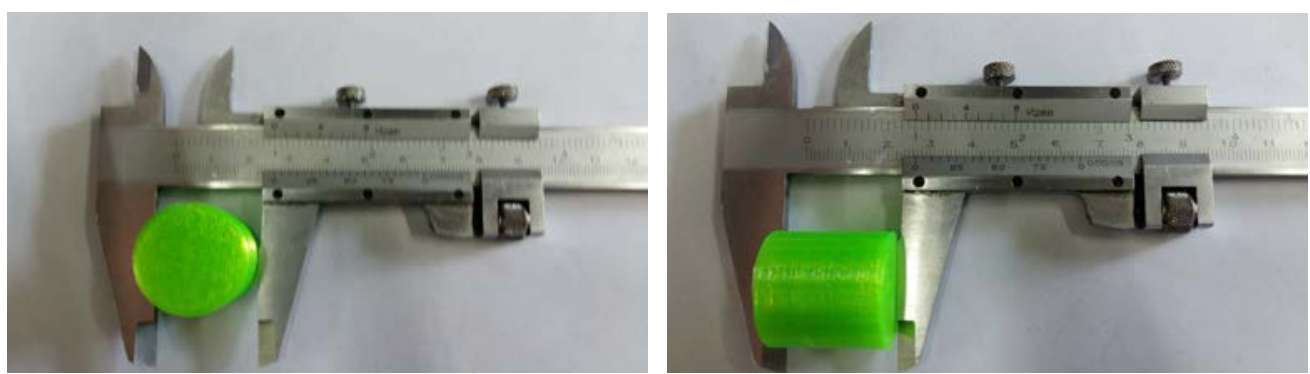

Gambar 6. Tabung

Tabel 2. Hasil Tabung

\begin{tabular}{ccc}
\hline Keterangan & Satuan & Penyimpangan \\
\hline Ukuran Design & $25.4 \times 25.4$ & $0.00 \%$ \\
Ukuran Hasil & $25.4 \times 25.4$ & \multirow{2}{*}{$26.64 \%$} \\
\hline Waktu Estimasi & 18 menit 1 detik & \\
Waktu Aktual & 22 menit 49 detik & $0.28 \%$ \\
\hline Panjang Filament & $2422 \mathrm{~mm}$ & \\
Berat Estimasi & $6.96 \mathrm{~g}$ & \\
Berat Aktual & $6.98 \mathrm{~g}$ & \\
\hline
\end{tabular}

- Prima Segitiga
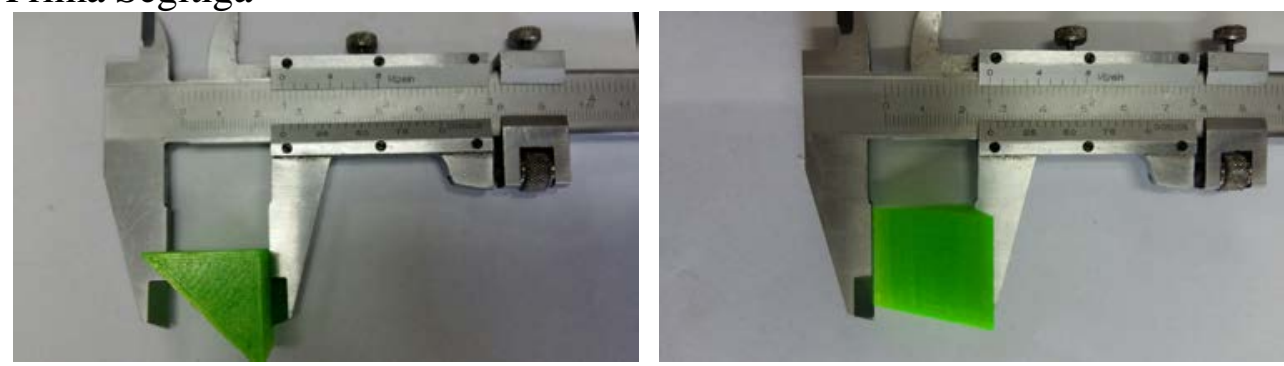

Gambar 7. Prisma segitiga

Tabel 3. Hasil prisma segitiga

\begin{tabular}{ccc}
\hline Keterangan & Satuan & Penyimpangan \\
\hline Ukuran Design & $25.4 \times 25.4 \times 25.4$ & $5.79 \%$ \\
Ukuran Hasil & $24.9 \times 24.9 \times 24.9$ & \multirow{2}{*}{$24.13 \%$} \\
\hline Waktu Estimasi & 14 menit 30 detik & \\
Waktu Aktual & 18 menit 0 detik & $2.05 \%$ \\
\hline Panjang Filament & $1866 \mathrm{~mm}$ & \\
Berat Estimasi & $5.36 \mathrm{~g}$ & \\
Berat Aktual & $5.25 \mathrm{~g}$ &
\end{tabular}

- Piramida
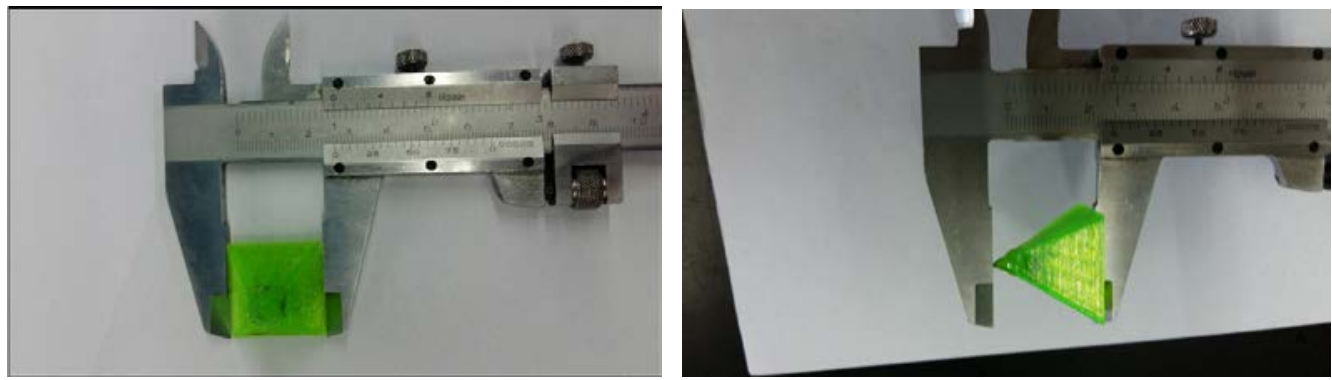

Gambar 8. Piramida 
Tabel 4. Hasil Piramida

\begin{tabular}{ccc}
\hline Keterangan & Satuan & Penyimpangan \\
\hline Ukuran Design & $25.4 \times 25.4 \times 25.4$ & \multirow{2}{*}{$3.98 \%$} \\
Ukuran Hasil & $24.6 \times 24.6 \times 26$ & \multirow{2}{*}{$12.26 \%$} \\
\hline Waktu Estimasi & 12 menit 55 detik & \\
Waktu Aktual & 14 menit 32 detik & \multirow{2}{*}{$6.90 \%$} \\
\hline Panjang Filament & $1302 \mathrm{~mm}$ & \\
Berat Estimasi & $3.74 \mathrm{~g}$ & \\
Berat Aktual & $3.48 \mathrm{~g}$ & \\
\hline
\end{tabular}
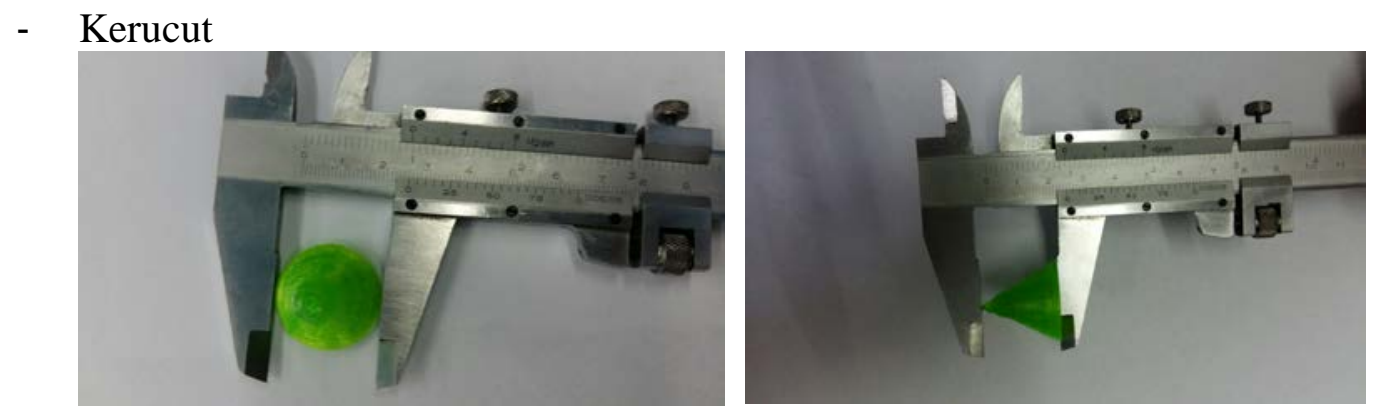

Gambar 9. Kerucut

Tabel 5. Hasil Kerucut

\begin{tabular}{ccc}
\hline Keterangan & Satuan & Penyimpangan \\
\hline Ukuran Design & $25.4 \times 25.4$ & \multirow{2}{*}{$13.87 \%$} \\
Ukuran Hasil & $25.1 \times 24.3$ & \\
\hline Waktu Estimasi & 11 menit 24 detik & $4.38 \%$ \\
Waktu Aktual & 11 menit 54 detik & \\
\hline Panjang Filament & $1038 \mathrm{~mm}$ & \multirow{2}{*}{$8.05 \%$} \\
Berat Estimasi & $2.98 \mathrm{~g}$ & \\
Berat Aktual & $2.74 \mathrm{~g}$ & \\
\hline
\end{tabular}

\section{Hasil Analisis Objek}

Dari table-tabel analisis diatas didapat hasil perbedaan berikut:

- Berat

Berat hasil lebih berat daripada berat aktual. Hal ini dikarenakan pada saat pemanasan filament terjadi penguapan. Sehingga nilai beban berbeda atau tidak akurat.

- Ukuran

Perbedaan ukuran yang terjadi pada objek dikarenakan suhu berubah ubah pada saat proses printing, sehingga lelehan filament tidak merata.

- Waktu printing

Perbedaan waktu pada saat proses printing dikarenakan waktu yang ditampilkan pada software merupakan estimasi waktu. Sehingga terdapat perbedaan waktu dari software dengan aktualnya.

- Bentuk

Pada bentuk piramada dan kerucut terdapat kegagalan pada bagian yang mengerucut. Hal ini dikarenakan pada saat pengerjaan bagian yang mengerucut filament belum mengeras atau masih meleleh sehingga bentuk menjadi tidak sempurna.

\section{KESIMPULAN}

- Mesin fused deposition modelling tidak dapat membentuk 3d model dengan dimensi yang terlalu kecil. 
- Dengan software yang digunakan pada mesin fused deposition modelling dapat mendeteksi suhu pada saat proses printing.

- Hasil dari fused deposition modelling mengalami penyimpangan rata - rata pada ukuran sebesar $5.204 \%$, waktu sebesar $18.274 \%$, dan beban sebesar $3.704 \%$.

- Sistem kontrol dapat bekerja dengan baik, dapat dilihat pada sumbu X,Y,Z dapat menentukan titik Home dan dapat bergerak sesuai perintah yang diberikan.

\section{DAFTAR PUSTAKA}

[1] A.C. Brown, D. de Beer2 \& P. Conradie, Januari 2014, "Development of Stereolithography (STL) Input and Computer Numerical Control (CNC) Output Algorithm For an Entry-Level 3-D Printer”, Journal of Industrial Engineering, $\quad$ Vol 25, No 2, Hal 42.

[2] Evans, Brians. 2012. Practical 3D Printers. Springer Science Business Media New York, 233 Spring Street.

[3] Frank W. Liou, “Rapid Prototyping and Engineering Applications” Hal 215.

[4] Susilo Adi Widyanto, Januari 2008 "Pengembangna Teknologi Rapid Prototyping untuk Pembuatan Produk - Produk Multi material”, Vol 2, No 02, Hal 10.

[5] http://www.livescience.com/39810-fused-deposition-modeling.html, Pengertian Fused Deposition Modelling, Diakses Tanggal 03 April 2016.

[6] https://www.techopedia.com/definition/1756/power-supply, Penjelasan Power supply, Diakses Tanggal 03 April 2016.

[7] https://sites.google.com/site/informasiterbarusekali/pengertian-mikrokontroller, Penjelasan Mikrokontroler, Diakses Tanggal 03 April 2016.

[8] http://elektronika-dasar.web.id/limit-switch-dan-saklar-push-on/, Penjelasan Limit Switch, Diakses Tanggal 03 April 2016.

[9] http://www.explainthatstuff.com/heating-elements.html, Penjelasan Penghantar Suhu dan Sensor, Diakses Tanggal 03 April 2016.

[10] http://www.ilmu.8k.com/pengetahuan/stepper.htm, Penjelasan motor stepper, Diakses Tanggal 06 April 2016.

[11] http://elib.unikom.ac.id/files/disk1/494/jbptunikompp-gdl-agusnandar-24682-3-babii.pdf, Penjelasan Sistem Kontrol, Diakses Tanggal 06 April 2016.

[12] http://www.custompartnet.com/wu/fused-deposition-modeling, Gambar Proses Fused Deposition Modelling, Diakses Tanggal 03 April 2016.

[13] http://www.mendocinobaby.com/b4d974-12v-30a-power-supply-save-more, Gambar Power Supply, Diakses Tanggal 06 April 2016.

[14] https://www.arduino.cc/en/Main/ArduinoBoardMega, Gambar Arduino Mega 2560, Diakses Tanggal 06 April 2016.

[15] http://www.aliexpress.com/store/product/3D-printer-Makerbot-reprap-extrusion-head-extruder -nozzle-upgrade-kit-MK8-works-with-3D-printer/1630163_32264098297.html, Gambar Extrude, Diakses Taggal 06 April 2016.

[16] http://www.automationtechnologiesinc.com/products-page/stepper-motors/nema-23-bipolarstepper-motor-185-oz-in-quarter-inc-dual-shaft-with-a-flat, Gambar motor stepper, Diakses Tanggal 06 April 2016. 